\title{
Pediatric Takayasu Vasculitis with Extensive Vascular Involvement
}

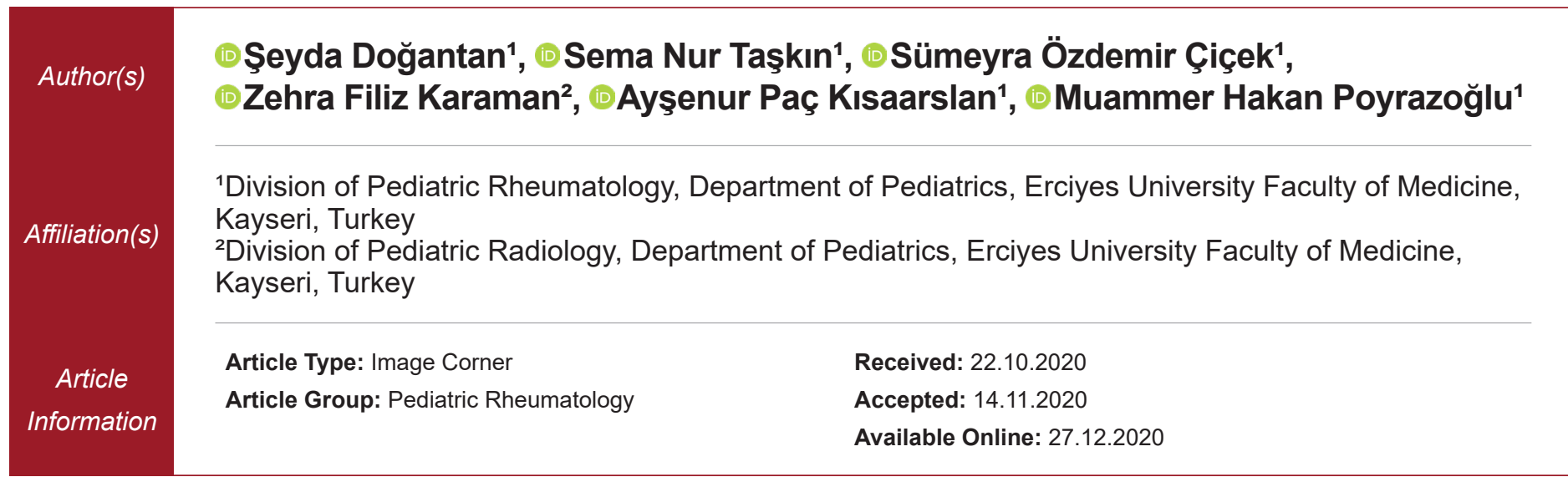

Cite this article as: Doğantan Ş, Taikın SN, Özdemir ÇiçekS, Kahraman ZF, Paç Kısaarslan A, Poyrazoğlu MH. Pediatric Takayasu Vasculitis with Extensive Vascular Involvement. J Pediatr Acad 2020; 1: 105-106.

An 11-year-old female known to healthy children admitted to the hospital with chest pain for a month. The pain spread from left shoulder to back and increased at night. Her pain did not change with motion and was relieved with non-steroidal anti-inflammatory drugs (NSAIDs). She had no cough, fever, and weight loss. She had no family history of cardiac, cerebrovascular, or rheumatologic disease. Measurements of blood pressure were 100/50 $\mathrm{mmHg}$ in the right upper extremity, $90 / 60 \mathrm{mmHg}$ in the left upper extremity, $90 / 50 \mathrm{mmHg}$ in the right lower extremity, $90 / 60 \mathrm{mmHg}$ in the left lower extremity. Other vital signs and physical examination findings were normal. Laboratory values; hemoglobin was $8.6 \mathrm{~g} / \mathrm{dl}$, erythrocyte sedimentation rate was $91 \mathrm{~mm} / \mathrm{hour}$ (normal 0-20 mm/h), $\mathrm{C}$-reactive protein was $37 \mathrm{mg} / \mathrm{dl}$ as abnormal findings. The other evaluations for infectious and malignancies were non-significant. Anti-nuclear antibody, Anti-neutrophil cytoplasmic antibodies, anti-ds-DNA, anti-phospholipid antibodies were in the normal range. Echocardiographic findings were normal. Magnetic Rosenans (MR) angiography was performed with a preliminary diagnosis of vasculitis due to unexplained high acute phase reactants and upper and lower extremity blood pressure differences. The vessel wall irregularities were observed in both internal carotid arteries, vertebral arteries, vertebral basilar system, and thoracic aorta (Figure 1,2,3). Bilateral renal arteries narrowing were observed at the exit level from the aorta (Figure 2). The patient was treated with steroid, cyclophosphamide, and mycophenolate mofetil. Six months later, new artery involvement was detected, and tocilizumab was started.

Takayasu arteritis is diagnosed with angiography (CA, CTA, and MRA) of the aorta, its main branches or pulmonary arteries showing aneurysm/dilatation, narrowing, occlusion, or a thickened arterial wall not due to other causes, plus one of the five following criteria: pulse deficit or claudication, four limb blood pressure inconsistencies, bruits, hypertension, and elevated acute phase reactants. ${ }^{1}$ The management of TA is made according to the rare pediatric vasculitides consensus report. ${ }^{2}$ Our patient's most important feature was nonspecific chest pain, and elevated levels of acute-phase reactants cannot be explained due to other reasons.

TA should be investigated in a case with unexplained silent clinical findings and high acute phase reactants. 


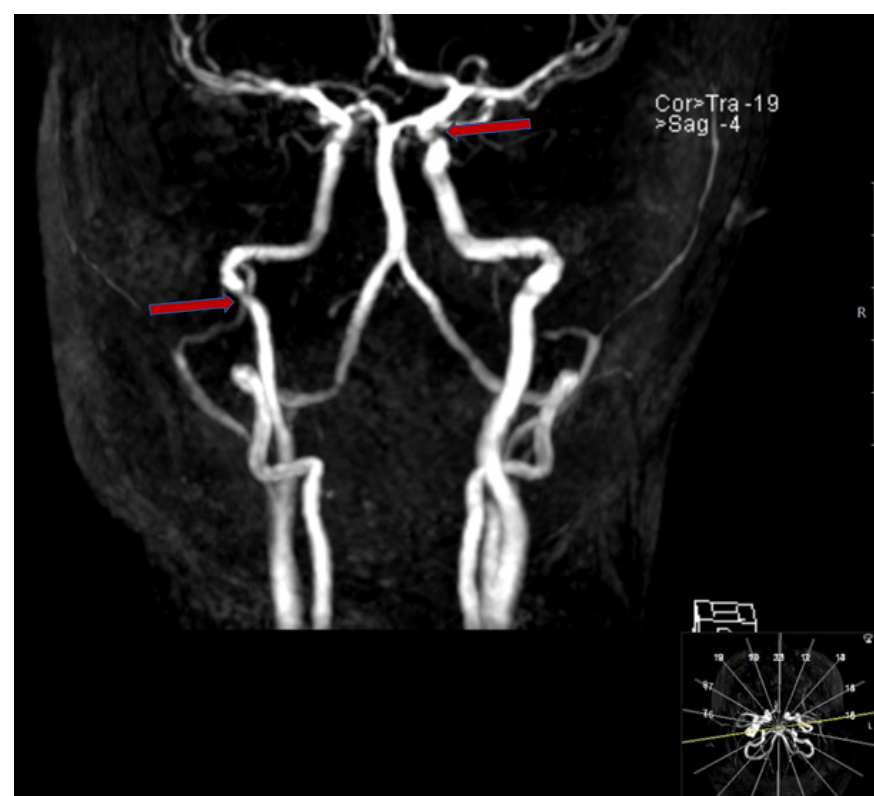

Figure 1. MR Angiography: Wall irregularities are observed in both internal carotid arteries, both vertebral arteries, and the vertebral basilar system

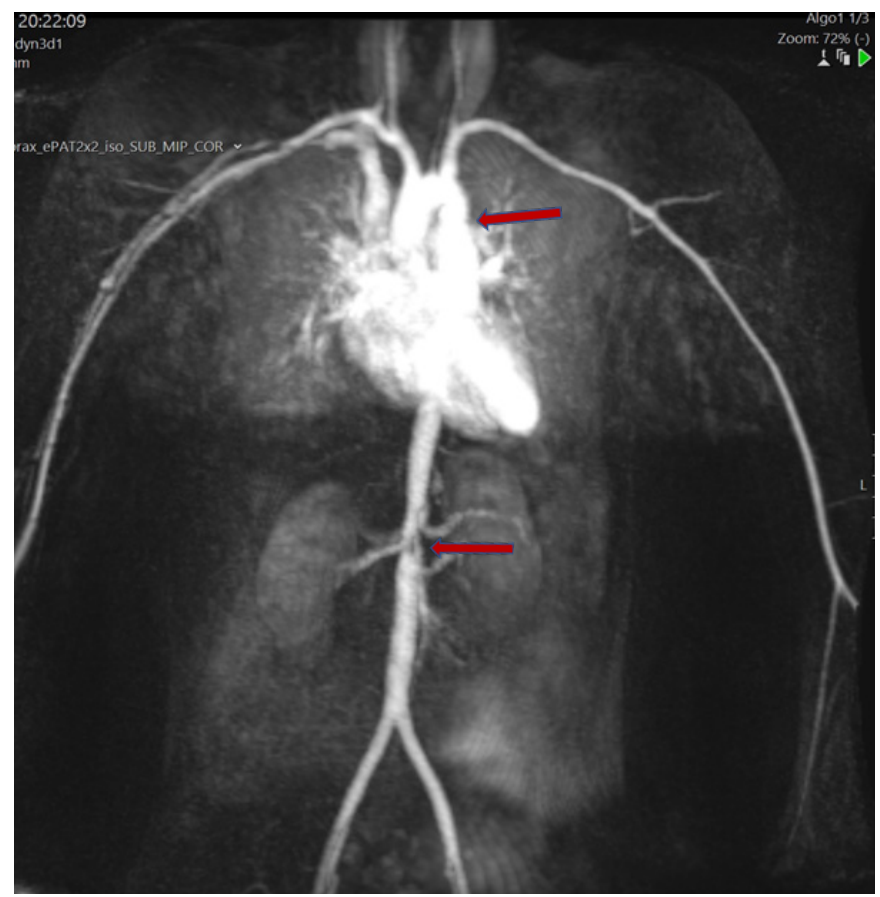

Figure 2. MR Angiography: At the exit of the left common carotid artery arch from the aorta, partly narrowing and wall irregularities are observed in the thoracic aorta. The abdominal aorta was observed with a markedly narrowed

Author Contributions: All of the authors declare that they have all participated in the design, execution, and analysis of the paper, and that they have approved the final version.

Conflict of Interest Statement: The authors have no conflicts of interest to declare.

Financial Disclosure: The authors declared that this study has received no financial support.

Informed Consent: Written informed consent was obtained from all participants who participated in this study.

Peer-review: Externally peer-reviewed.

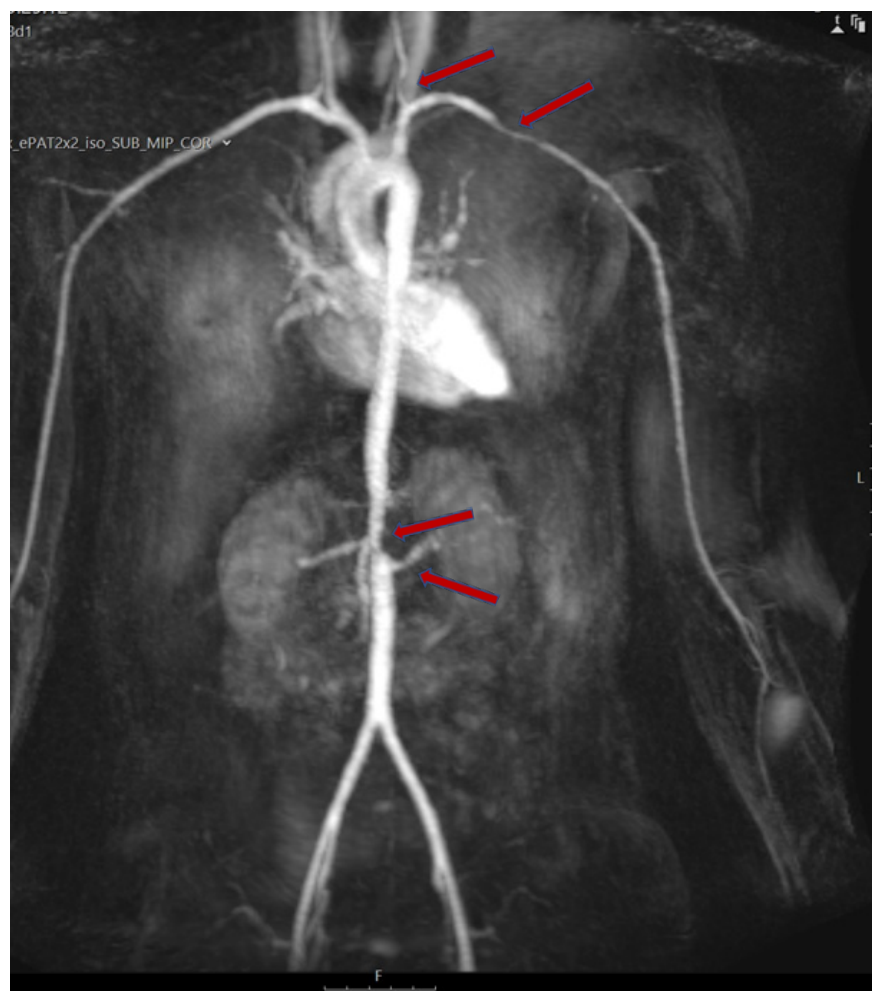

Figure 3. MR Angiography: The left common carotid artery was observed to be markedly narrowed from its exit from the artery. In the middle part of the left subclavian artery, an irregularity that caused significant stenosis in the lumen was observed in a $15 \mathrm{~mm}$ segment. There was an irregularity in the abdominal aorta that caused a minimal narrowing of the renal arteries and before the exit level. There is also an irregularity in the proximal left renal artery causing minimal narrowing of the lumen

\section{References}

1. Ozen S, Pistorio A, lusan SM, et al. EULAR/PRINTO/PRES criteria for Henoch-Schönlein purpura, childhood polyarteritis nodosa, childhood Wegener granulomatosis and childhood Takayasu arteritis: Ankara 2008. Part II: Final classification criteria. Ann Rheum Dis. 2010;69:798-806. [CrossRef]

2. de Graeff N, Groot N, Brogan P, et al. European consensusbased recommendations for the diagnosis and treatment of rare paediatric vasculitides - the SHARE initiative. Rheumatology (Oxford). 2019;58:656-671. [CrossRef] 